\title{
Factors and conditions influencing the willingness of Irish consumers to try insects: a pilot study
}

\author{
B. Kane ${ }^{1}$, M. Dermiki ${ }^{1 \dagger}$ \\ ${ }^{1}$ Faculty of Science, Institute of Technology Sligo, Ash Lane, Sligo, Ireland
}

Abstract

Entomophagy is being explored as a sustainable food source in Western countries to combat the ever-increasing effects of climate change. Studies conducted in various European countries determine the factors affecting willingness to consume insects. The current study aims to gain the first insight on this topic in Ireland, a country with a long farming tradition. A survey including open- and closed-ended questions was developed and sent to students and staff of an institute of technology in the West of Ireland. The willingness to consume insects and the factors affecting willingness to consume them under different conditions were assessed. It was found that less neophobic males who do not follow a particular diet were most receptive to entomophagy. People who were willing to try insects were less willing if the insects were to be eaten whole. People who were not willing were more inclined to do so if they were disguised or used to feed livestock. Food neophobia, disgust and safety concerns were barriers to acceptance. Tasty products containing disguised insects in familiar foods are the most likely to be accepted. Education and taste tests are recommended first steps to introducing entomophagy. Using insects to feed livestock has the potential to improve acceptance of entomophagy by introducing insects in the supply chain. However, further research should be conducted to assess acceptance of this amongst Irish farmers. The current study agrees with findings of studies conducted in other European countries and reveals the conditions under which insects could become acceptable among Irish consumers.

Keywords

Disgust • entomophagy $•$ food neophobia $・$ Irish consumers $・$ willingness to consume

\section{Introduction}

While human population worldwide is rising and the demand for food is increasing, there is a reduction in the available resources to produce food (Premalatha et al., 2011). Moreover, animal and dairy protein production is reported to have a high carbon footprint due to increased greenhouse gas emissions (Clune et al., 2017). Therefore, alternative environmentally sustainable protein sources are being explored. The need for sustainable food sources is further led by the United Nations sustainable development goal 12 which highlights the need for responsible consumption and production, and goal 13 which calls for action by all countries towards climate change (United Nations, 2019). The European Union (EU) has set targets for greenhouse gas emissions coming from a number of sources, including agriculture (Department of Communications, Climate Action and Environment, 2018). One approach to overcome this problem would be the use of sustainable sources of proteins such as insects, which are widely adopted elsewhere, but not as popular in the Western world (Bessa et al., 2017), including Ireland. Insects are being considered as a more sustainable alternative to animal proteins due to the lower greenhouse gas emissions, less resources, transport, water and land use associated with their production, due to their positive contribution to animal welfare and due to the low cost, high nutritional value protein they can provide in the diet (Godfray et al., 2010; Schösler et al., 2012; Dossey et al., 2016; Akhtar \& Isman, 2018; Baiano, 2020).

The nutritional value of insects depends on the species, the stage of metamorphosis, their diet and their origin (Finke \& Oonincx, 2014; Bessa et al., 2017). Kouřimská \& Adámková (2016) and more recently Gere et al. (2019) reviewed the published data on nutritional composition of various insect species and compared them with the nutritional composition of meat from various sources. They found that insects, which belong to the arthropod class, the largest of the animal phyla 
(Wigglesworth, 2020), generally have a better nutritional profile than other meats. For example, protein content (based on dry matter) varied from $15 \%$ up to $81 \%$, and protein digestibility of insects varied from $76 \%$ to $96 \%$, comparable to egg $(95 \%)$ and slightly lower than beef (98\%), while higher than plant proteins (Kouřimská \& Adámková, 2016). Overall, insects are reported to contain high amounts of protein while also containing a significant amount of fibre, minerals and vitamins (Payne et al., 2016), making them a nutritionally viable food source. However, most of the fibre is attributed to the chitin which could have negative effects on protein digestion, and therefore it should be removed (Belluco et al., 2013).

Entomophagy, the term used to describe the practice of eating insects, is widespread in many countries around the world (East Asia, parts of Africa and South America). However, it is currently less popular in most Western countries (Bessa et al., 2017), and for this reason, several studies have been conducted in order to explore the factors that affect willingness to consume insects among Europeans and North Americans. The main factors, as found in these studies, were related to the individual, their environment and the characteristics of the product.

In relation to the individual, a number of factors have been identified: age, gender, subject of study, knowledge of entomophagy, implicit associations, interests, dietary habits, food neophobia, disgust and whether a person has previously consumed insects all play a role in acceptance of entomophagy. Specifically, those who study environment and food sciences have been found to have a higher intention to consume insect-based products (Verbeke, 2015; Menozzi et al., 2017), along with those interested in health (Verbeke, 2015; Schlup \& Brunner, 2018). A desire to reduce meat consumption and having a weak attachment to meat have been shown to be other dietary patterns that increase consumers' likelihood of being receptive to insects (Verbeke, 2015). Specifically, Verbeke (2015), who attempted to understand the profile of the consumers from Belgium who would consume insects, found that young men with weak attachment to meat, concerned about the environmental impact of their food and who are willing to try novel foods are the group of consumers most willing to accept insects. Several studies have identified food neophobia as a factor which decreases willingness to consume insects in the West (Hartmann et al., 2015; Verbeke, 2015; Tan et al., 2016a; Schlup \& Brunner, 2018; Wilkinson et al., 2018; Orsi et al., 2019). Interestingly, food neophobia had no effect on consumers from Sweden possibly due to the positive media coverage of the matter in this country (Schlup \& Brunner, 2018). This finding implies that social and environmental factors affect entomophagy as well.

Social and environmental factors have been investigated in a number of studies, as seen below. A cross-cultural comparison study between Germany and China revealed that although insect foods are not popular in either of these countries, they are more familiar and socially accepted in China as insects are a part of their history and culture (Hartmann et al., 2015). Another cross-cultural comparison between Thailand and the Netherlands found that culture influences knowledge and individual experiences of insects as food (Tan et al., 2015). The Thai participants, for whom insect eating was a part of their culture, knew more about the variety of edible insects, their different tastes and methods for cooking, and so found them less disgusting and more acceptable. The effects of this awareness and knowledge of entomophagy were further explored by Verneau et al. (2016) who found that knowledge increases intention to eat insects in two Western cultures, that is, Denmark and Italy. Interestingly, Danes were more willing to eat insects than Italians, possibly because Italians have a rich food culture which would make them less open to novel foods (Verneau et al., 2016). This difference in willingness to consume was further supported by the findings of Piha et al. (2018) who explored how knowledge affected willingness to buy insect foods, and this willingness differed between residents in Northern and Central Europe, with Northern Europeans being more positive towards insect foods. The cross-cultural studies described here show that acceptability of entomophagy depends to a large degree on the cultural background of people, and that findings on factors affecting entomophagy in one European country are not directly translated to others. In Ireland, the only study conducted in relation to entomophagy focused mainly on whether exposure to intellectual appeal (text) or social appeal (video) would change the rated disgust of consuming a cricket (Sheppard \& Frazer, 2015). The aim of that study, however, was not to draw a profile of Irish consumers willing to consume insects; therefore, this is still an area that needs to be explored.

An important finding when reviewing the studies on factors affecting willingness to consume insects was the fact that acceptance depended on the products' characteristics. In particular, taste (Tan et al., 2016a) but also whether insects were disguised or not in the product played a significant role in the acceptability of the final products (Deroy et al., 2015). Several consumer profiling studies have found that people are more willing to consume insects if they are processed and hidden in familiar and appropriate products (Gmuer et al., 2016; Sogari et al., 2017; Myers \& Pettigrew, 2018; Schlup \& Brunner, 2018; Wilkinson et al., 2018; Jensen \& Lieberoth, 2019). The more invisible the insects, the better as this improves familiarity of the product (Gmuer et al., 2016), reducing the effects of disgust and food neophobia ( $\mathrm{La}$ Barbera et al., 2018).

The aim of the current study is to understand the factors that affect willingness to consume insects among Irish consumers. One specific objective is to determine how some of the factors investigated in previous studies such as sociodemographic 
characteristics, previous experience, knowledge of entomophagy, food habits and behaviour related to food affect willingness to try insects in an Irish sample. Another objective of this study, which also constitutes its novelty, is to explore the conditions under which this segment of Irish consumers would consume insects. This is a pilot study which aims to guide educational/promotional strategies and develop further consumer acceptance studies in Ireland.

\section{Methodology}

\section{Survey development}

An online survey was developed for this study and was sent to 3,000 staff and students of Institute of Technology Sligo, North West Ireland, in November 2018. The survey was live for 10 days. There were 338 responses in total; however, five responses were excluded, as they had not been completed according to guidelines, leading to the analysis of 333 responses. Most of the participants were Irish (80.5\%) with a small number of British, other European, American and Asian, and as revealed from a preliminary analysis of the data, these numbers were too low to observe any effects of nationality in any parameter studied. Therefore, it was decided to focus the analysis on Irish consumers only and the number of respondents considered for further analysis was 268 .

The first section of the survey determined participant characteristics and experiences related to entomophagy. Questions related to the demographic characteristics of the participants, such as their age, gender, nationality, diet, education level and area of study, were included. These factors were asked as it has been previously shown that these factors affected the willingness of participants from other Western countries to try insects (Hartmann et al., 2015; Verbeke, 2015; Schlup \& Brunner, 2018). Participants were asked whether they had heard of entomophagy and whether they had consumed insects before, as it has been found that those who have tried insects are more willing to consume them in the future (Schlup \& Brunner, 2018; Woolf et al., 2019).

The next part of the survey included statements to assess beliefs and behaviours relating to food, previously developed by Verbeke (2015). Participants were asked to rate their agreement to the statements on a 5-point Likert scale ( $1=$ completely disagree, 5 = completely agree). Specifically, their belief in the healthiness and nutritional benefits of meat (meat score) was assessed using five items: "eating meat is healthy", "eating meat is necessary for obtaining beneficial nutrients", "meat contains important nutrients", "meat is good for general health" and "meat is an important part of a healthy diet". Attitudes towards the health characteristics of food (health score) were assessed using three items, where $\mathrm{R}$ refers to reverse coded: "the healthiness of food has little impact on my food choices",
"I am very particular about the healthiness of the foods I eat" $(\mathrm{R})$, "I eat what I like and do not worry about the healthiness of food". Attention to environmental impact of food choices (environment score) was assessed with the statement, "When I buy foods I try to consider how they will affect the environment". Food neophobia was assessed using six items from the food neophobia scale developed by Pliner \& Hobden (1992): "I am constantly sampling new and different foods" (R), "I don't trust new foods", "If I don't know what is in a food I won't try it", "At parties I will try a new food" (R), "I am afraid to eat things I have never tried before", "I will eat almost anything" (R).

In order to investigate the conditions under which participants would consume insects, they were asked to indicate on a 5-point Likert scale the degree of likelihood ( $1=$ would definitely eat, 5 = would definitely not eat) that they would eat insects according to 12 "Willingness to Consume" conditions. These conditions were: "if they were whole", "if they were disguised", "if they were affordable", "if they were easily available", "if they were safe", "if they were nutritious", "as an alternative to meat", "due to the health benefits", "due to the environmental benefits", "if they were tasty", "if my family and friends were eating them" and "if the meat I was eating had been fed insects".

Open-ended questions were employed in this survey in order to explore further the factors affecting willingness to consume insects in Ireland, as when the study took place (November 2018) no previous research was available. The open-ended questions assessed participants' opinion about entomophagy, the rationale behind answering "no" to the question "would you be willing to try insects" and any additional factors they felt would influence their decision to eat or not to eat insects.

The study was approved to proceed by the Research Ethics Committee of the Faculty of Science in Institute of Technology Sligo, Ireland.

\section{Data analysis}

Statistical analysis of quantitative data was conducted using SPSS (IBM version 24, Armonk, NY, USA: IBM Corp.). For questions such as "nationality" and "what course do you study", no categories were given on the survey, rather, categories were created during the analysis stage. For nationality, six categories were created - Irish, UK, Canadian/American, other European, African and Asian. The diverse range of courses studied by the participants was condensed into seven categories: nutrition/ food/health science, environmental science, other science, engineering, computer science, English/arts and business. Diet types were categorised as follows: vegetarian, vegan, not specific, gluten free/coeliac, pescatarian, healthy/slimming, reduced meat and halal.

The sociodemographic characteristics of the participants can be seen in Table 1. The answers to the reverse coded 
Table 1: Sociodemographic characteristics of the participants $(\mathrm{N}=268)$ (Irish only) in the online survey

\begin{tabular}{|c|c|c|}
\hline Variable & Categories & Percentage (\%) \\
\hline \multirow[t]{6}{*}{ Age, years } & 20 or under & 24.6 \\
\hline & $21-30$ & 35.1 \\
\hline & $31-40$ & 17.5 \\
\hline & $41-50$ & 14.2 \\
\hline & $51-60$ & 7.1 \\
\hline & 61 or over & 1.5 \\
\hline \multirow[t]{2}{*}{ Gender } & Male & 46.6 \\
\hline & Female & 53.4 \\
\hline \multirow[t]{3}{*}{ Highest level of education } & Secondary & 37.7 \\
\hline & Third level & 42.5 \\
\hline & Postgraduate & 19.8 \\
\hline \multirow[t]{7}{*}{ Course } & Nutrition/food/health & 36.7 \\
\hline & Environmental science & 6.8 \\
\hline & Other science & 26.6 \\
\hline & Engineering/design & 14 \\
\hline & Computer science & 10.1 \\
\hline & English/arts & 2.6 \\
\hline & Business & 2.6 \\
\hline \multirow[t]{2}{*}{ Heard of entomophagy } & Yes & 60.8 \\
\hline & No & 39.2 \\
\hline \multirow[t]{2}{*}{ Eaten insects previously } & Yes & 13.4 \\
\hline & No & 86.6 \\
\hline \multirow[t]{2}{*}{ Willing to try insects } & Yes & 55.2 \\
\hline & No & 44.8 \\
\hline \multirow[t]{7}{*}{ Diet } & Vegetarian & 5.6 \\
\hline & Vegan & 0.4 \\
\hline & No specific diet & 89.6 \\
\hline & Gluten free/coeliac & 1.1 \\
\hline & Pescetarian & 0.7 \\
\hline & Healthy/slimming & 1.1 \\
\hline & Reduced meat & 1.5 \\
\hline
\end{tabular}

Note: Values presented in bold represent the majority in each group.

questions were transformed (so that all questions represented neophobia and health concern) and the averages of each participant's answers for the meat, health and neophobia questions were calculated. The internal consistency of the various constructs that belonged in each group was assessed by calculating Cronbach's alpha (Table 2). These questions were then grouped to form scores named "meat score", "health score", and "neophobia score". The question related to environmental concern was referred to as an "environment score" for analysis.
The effect of the sociodemographic characteristics of the participants (age, gender, course, diet, education level), previous experience with entomophagy, knowledge of entomophagy, meat score, health score, neophobia score and environment score on willingness to try insects was tested using non-parametric tests (chi-square, MannWhitney $U$ when comparing two groups, Kruskal-Wallis for comparison of more than two groups) due to the fact that data were not normally distributed. The effect of the above factors and willingness to try was further tested on the willingness to consume conditions. Spearman's correlation was used to test the effect of age, environment score, meat score, health score and neophobia score. The Kruskal-Wallis test was used for nationality, education level, course type and diet, and the Mann-Whitney $U$ test was used for gender, previous knowledge of entomophagy, previous experience with entomophagy and willingness to try. Post hoc analyses (pairwise comparisons using the Dunn procedure [Dunn, 1964]) were performed on the significant findings of the Kruskal-Wallis test to find out where the significant differences existed. The importance ranking of the 12 willingness to try conditions was assessed using the Friedman test and further comparison was conducted using the Bonferroni test.

For the qualitative data from the open-ended questions, a deductive approach was employed to create themes from the codes generated when analysing the answers of the participants. The themes created were based on the literature around entomophagy. The frequencies of mentioning each code were reported.

\section{Results}

\section{Profile of participants}

The sociodemographic characteristics of the participants, course studied, diet and whether they had heard of entomophagy or had eaten insects can be seen in Table 1. The majority of the participants were Irish $(80.5 \%)$ with a small number of British, other European, American and Asian and as mentioned in the Methodology section, analysis focused on Irish participants only. As seen in Table 1, a slightly higher number of women $(53.4 \%)$ participated in the survey. The term other was also used in the questionnaire for gender but was not chosen by the participants. Most respondents were younger than 30 years $(60.6 \%)$. Most were students of nutrition/food and health science programmes $(36.7 \%)$ followed by other science programmes $(26.6 \%)$. While most participants $(61 \%)$ had heard of entomophagy, only $13.4 \%$ had consumed insects before, and slightly more than half were willing to try insects $(55.2 \%)$. Among those who had consumed insects, more 
Table 2: Reliability of the meat, health and neophobia questions assessed using Cronbach's alpha

\begin{tabular}{|c|c|c|c|}
\hline Score & Cronbach's alpha $(\alpha)$ & Mean \pm s.d. & $\mathbf{R}^{*}$ \\
\hline Meat score & 0.89 & & \\
\hline 1. Eating meat is healthy & & $3.81 \pm 0.91$ & 0.754 \\
\hline 2. Eating meat is important for obtaining necessary nutrients & & $3.27 \pm 1.21$ & 0.625 \\
\hline 3. Meat contains important nutrients & & $4.13 \pm 0.78$ & 0.663 \\
\hline 4. Meat is good for general health & & $3.71 \pm 0.99$ & 0.81 \\
\hline 5. Meat is an important part of a healthy diet & & $3.52 \pm 1.13$ & 0.817 \\
\hline Health score & 0.68 & & \\
\hline 1. The healthiness of food has little impact on my food choices & & $2.35 \pm 1.18$ & 0.443 \\
\hline 2. I am very particular about the healthiness of the food I eat & & $2.89 \pm 1.15$ & 0.439 \\
\hline 3. I eat what I like and do not worry much about the healthiness of food & & $2.47 \pm 1.13$ & 0.622 \\
\hline Neophobia score & 0.81 & & \\
\hline 1. I am constantly sampling new and different foods & & $2.65 \pm 1.16$ & 0.537 \\
\hline 2. I don't trust new foods & & $2.09 \pm 1.04$ & 0.593 \\
\hline 3. If I don't know what is in a food, I won't try it & & $2.71 \pm 1.27$ & 0.481 \\
\hline 4. At parties I will try a new food & & $2.34 \pm 1.11$ & 0.552 \\
\hline 5. I am afraid to eat things I have never had before & & $2.23 \pm 1.18$ & 0.701 \\
\hline 6. I will eat almost anything & & $2.75 \pm 1.29$ & 0.547 \\
\hline
\end{tabular}

Note: The number of the item corresponds to the order of appearance on the survey. Mean \pm s.d. for each item and inter-item correlation $\left(R^{*}\right)$ (number of responses $\mathrm{N}=268$ ).

men $(72.2 \%)$ had done so than women. In the case of the question, have you heard of entomophagy, positive answers were almost equally spread between genders with $52.1 \%$ being male participants.

\section{Reliability of questionnaires}

Table 2 presents the reliability of the three scores (meat, health and neophobia). As seen in Table 2, Cronbach's alpha is higher than 0.70 for the neophobia score and meat score, but is lower for the health score at the value of 0.68 . The lower Cronbach's alpha for the health score could be attributed to the low inter-item correlation $\left(R^{*}\right)$ from the items: "I am very particular about the healthiness of the food I eat" and "The healthiness of food has little impact on my food choices". The health score, however, was calculated as a combination of the three items, unless stated otherwise.

\section{Factors affecting willingness to try insects}

Table 3 presents a summary of the various factors affecting willingness of the participants to consume insects. Significance levels and the statistical tests used can also be seen.

As seen in Table 3, more men (57.4\%) were willing to try insects compared to women. This difference between the two genders, as revealed from the chi-squared test, was statistically significant $(P<0.001)$. There was no effect of education level, course type and age on willingness to try. Age data were analysed comparing the six age groups using the Kruskal-Wallis test, and they were also separated into two groups of participants younger than 30 (160 participants) and older than 31 years (108 participants) and compared using the Mann-Whitney test; however, no effect of age was observed in the willingness to try regardless of the method of analysis used. There was a significant effect of diet $(P=0.030)$, as higher percentages of vegetarians $(80 \%)$ and vegans $(100 \%)$ were not willing to try insects, whereas among those who do not follow a specific diet slightly more than half $(58.3 \%)$ were. In terms of the dietrelated behaviour, there was no effect on the meat score, environment score or health score; however, there was a significant effect on the food neophobia score $(P<0.0001)$. People who were not willing to try insects had higher scores for food neophobia $(2.89 \pm 0.81)$ compared to those who were willing to try insects $(2.11 \pm 0.69)$. Previous knowledge and previous experience significantly affected willingness to try as a higher percentage of people who had heard of entomophagy $(67.5 \%)$ were willing to try insects compared to the $36.2 \%$ of those who had not heard the term (Table 3 ). Among those who had already tried insects, $91.7 \%$ would try them again, whereas among those who had not tried insects before only $49.6 \%$ were willing to try them. 
Table 3: Effect of sociodemographic characteristics (age, gender, diet, education level and course type) previous knowledge and experience, neophobia, health, meat and environment scores on willingness to try insects

\begin{tabular}{|c|c|c|c|}
\hline & \multicolumn{2}{|c|}{ Willingness to try } & \multirow{3}{*}{$\begin{array}{c}\text { Statistical test } \\
\text { Significance level }\end{array}$} \\
\hline & Yes $(N=148)$ & No $(N=120)$ & \\
\hline & Percentage (\%) & Percentage (\%) & \\
\hline Age, years & & & Kruskal-Wallis \\
\hline$<20$ & 23 & 29.2 & $P=0.098$ \\
\hline $21-30$ & 38.5 & 35 & \\
\hline $31-40$ & 19.3 & 15 & \\
\hline $41-50$ & 12.6 & 14.2 & \\
\hline $51-60$ & 6.7 & 6.7 & \\
\hline$>61$ & 3 & 0 & \\
\hline Gender & & & Chi-square \\
\hline Male & 57.4 & 33.3 & $P<0.001$ \\
\hline Female & 42.6 & 66.7 & \\
\hline Diet & & & Kruskal-Wallis \\
\hline Vegetarian & 2 & 8.1 & $P=0.03$ \\
\hline Vegan & 0 & 0.7 & \\
\hline No specific diet & 94.6 & 67.6 & \\
\hline Gluten free/coeliac & 0.7 & 1.4 & \\
\hline Pescetarian & 0 & 1.4 & \\
\hline Healthy/slimming & 0.7 & 1.4 & \\
\hline Halal & 0 & 0 & \\
\hline Reduced meat & 2 & 0.7 & \\
\hline Previous knowledge & & & Chi-square \\
\hline Yes & 74.3 & 44.2 & $P<0.001$ \\
\hline No & 25.7 & 55.8 & \\
\hline Previous experience & & & Chi-square \\
\hline Yes & 22.3 & 2.5 & $P<0.001$ \\
\hline No & 77.7 & 97.5 & \\
\hline Education level & & & Kruskal-Wallis \\
\hline Secondary & 33.8 & 42.5 & $P=0.114$ \\
\hline Third & 43.9 & 40.8 & \\
\hline Postgraduate & 22.3 & 16.7 & \\
\hline Course type & & & Kruskal-Wallis \\
\hline Nutrition/food/health & 23.2 & 38.4 & $P=0.196$ \\
\hline \multicolumn{4}{|l|}{ science } \\
\hline Environmental science & 11.3 & 5.1 & \\
\hline Other science & 31.1 & 21 & \\
\hline Engineering/design & 16.9 & 15.2 & \\
\hline Computer science & 9 & 9.4 & \\
\hline English/arts & 5.1 & 5.1 & \\
\hline \multirow[t]{2}{*}{ Business } & 3.4 & 5.8 & \\
\hline & \multicolumn{2}{|c|}{ Mean \pm s.d. } & Mann-Whitney \\
\hline Neophobia score & $2.11 \pm 0.69$ & $2.89 \pm 0.81$ & $P<0.05$ \\
\hline
\end{tabular}


Table 3: (continued)

\begin{tabular}{lccc}
\hline & \multicolumn{2}{c}{ Willingness to try } & \multicolumn{1}{c}{ Statistical test } \\
\cline { 2 - 3 } & Yes $(\mathbf{N}=\mathbf{1 4 8})$ & No $(\mathbf{N}=\mathbf{1 2 0})$ & Significance level \\
\cline { 2 - 3 } & Mean \pm s.d. & Mean \pm s.d. & $P>0.05$ \\
\hline Health score & $2.61 \pm 0.55$ & $2.66 \pm 0.65$ & $P>0.05$ \\
Meat score & $3.69 \pm 0.83$ & $3.56 \pm 0.88$ & $P>0.05$ \\
Environment score & $2.89 \pm 1.11$ & $2.65 \pm 1.21$ & \\
\hline
\end{tabular}

Note: Values in bold represent data where significant differences in willingness to try have been observed using the corresponding statistical tests. In each column total $\%$ adds to $100 \%$. Neophobia, health, meat and environment score are presented as Mean \pm s.d.

\section{Conditions under which participants are willing to consume insects}

The various conditions were ranked in terms of willingness as seen in Table 4. Participants would be most willing to try insects if they were tasty as this condition was ranked highest, followed by nutritious and safe. Participants would be less willing to try insects as an alternative to meat or if they were whole. The effect of the different factors on the willingness to consume conditions is further explained below.

\section{Gender}

As revealed from the Mann-Whitney test, there was a significant effect of gender on a number of conditions (Table 5) under which participants were willing to try insects. Overall,

Table 4: Mean rank of willingness to try conditions as revealed from a Friedman test to compare mean importance ranks

\begin{tabular}{lc}
\hline Willingness to try & Mean rank \\
\hline If they were tasty & 4.62 \\
If they were nutritious & 5.41 \\
If they were safe & 5.38 \\
If they were disguised in a food I like & 5.27 \\
If the meat I was eating had been fed insects & 6.13 \\
Due to the health benefits & 6.36 \\
Due to the environmental benefits & 6.82 \\
If my family and friends were eating them & 6.92 \\
If they were affordable & 7.25 \\
If they were easily available & 7.28 \\
As an alternative to meat & 8.14 \\
If they were whole & 8.41 \\
\hline
\end{tabular}

Note: Pairwise comparisons were conducted using the Bonferroni test. The higher the number the less willing they are to consume (willingness scale: 1 - would definitely eat vs. 5 - would definitely not eat). women were less willing than men to consume insects under most conditions such as if the insects were whole, if they were affordable, if they were easily available, if they were safe, if they were nutritious, if they were tasty and if the meat they were eating had been fed with insects (Table 5).

\section{Age}

There was an effect of age on the willingness to try conditions: as an alternative to meat and if insects were used to feed livestock. Under both conditions, higher percentages of younger people replied that they would definitely not eat versus people older than 30 years as seen in Table 6 .

\section{Education level and course type}

Education level affects only willingness to consume if insects were easily available $(P=0.042)$. From pairwise comparisons, there is a difference between secondary and postgraduate education, with higher percentages of people with secondary education $(32.7 \%)$ replying that they would definitely not eat versus $13.2 \%$ of those with postgraduate education giving the same response.

There was an effect of undergraduate course on the willingness to consume insects as whole (Kruskal-Wallis test). From the pairwise comparison, it was found that students who attend environmental science courses are more willing to try insects compared to those who study food/ nutrition and health science. However, there was no effect of course type at undergraduate or postgraduate level on any other condition.

\section{Diet}

There was an effect of diet on willingness to consume insects used as feed in livestock production (eating meat that had been fed with insects) and if they were disguised (see Supplementary data). Pairwise comparisons using the Dunn procedure showed that, compared to those who do not follow a specific diet, vegetarians were less willing to try meat that had been fed with insects. 
Table 5: Effect of gender on willingness to consume insects under different conditions using the Mann-Whitney test $($ male $=125$ and female $=143)$

\begin{tabular}{lcc}
\hline Willingness conditions & \multicolumn{2}{c}{ Mean willingness score \pm s.d. } \\
\cline { 2 - 3 } & Male & Female \\
\hline Willingness if they were whole & $3.12 \pm 1.41$ & $3.91 \pm 1.21$ \\
Willingness: if they were disguised in a food I like & $2.51 \pm 1.44$ & $2.80 \pm 1.47$ \\
Willingness: if they were affordable & $3.42 \pm 1.36$ & $\mathbf{2 . 8 6} \pm 1.35$ \\
Willingness: if they were easily available & $3.43 \pm 1.34$ & $\mathbf{2 . 8 6} \pm 1.34$ \\
Willingness: if they were safe & $\mathbf{2 . 8 7 \pm 1 . 4 2}$ & $\mathbf{2 . 5 2} \pm 1.43$ \\
Willingness: if they were nutritious & $\mathbf{2 . 8 9} \pm 1.41$ & $\mathbf{2 . 5 0} \pm 1.41$ \\
Willingness: as an alternative to meat & $3.66 \pm 1.32$ & $3.39 \pm 1.45$ \\
Willingness: due to the health benefits & $3.06 \pm 1.37$ & $2.82 \pm 1.33$ \\
Willingness: due to the environmental benefits & $3.18 \pm 1.41$ & $2.95 \pm 1.34$ \\
Willingness: if they were tasty & $\mathbf{2 . 6 9 \pm 1 . 4 9}$ & $\mathbf{2 . 2 8} \pm 1.43$ \\
Willingness: if my family and friends were eating them & $3.22 \pm 1.33$ & $3.01 \pm 1.36$ \\
Willingness: if the meat I was eating had been fed insects & $\mathbf{3 . 0 3} \pm 1.36$ & $\mathbf{2 . 6 7} \pm \mathbf{1 . 3 7}$ \\
\hline
\end{tabular}

Note: Values in bold show significant differences in willingness score between genders at $P<0.05$ as revealed by the Mann-Whitney test.

Table 6: Comparison of the two age groups $<30$ and $>31$ years in terms of their willingness to consume insects if the meat they were eating had been fed with insects and as an alternative to meat

\begin{tabular}{lcc}
\hline I would eat insects... & \multicolumn{2}{c}{ Age group } \\
\cline { 2 - 3 } & $<30$ years & \\
\hline If the meat I was eating & & \\
had been fed insects & 13.8 & 29.6 \\
$\quad$ Would definitely eat & 23.1 & 21.3 \\
Would possibly eat & 29.4 & 25.6 \\
Not sure & 11.9 & 6.5 \\
Would possibly not eat & 21.9 & 16.7 \\
$\quad$ Would definitely not eat & & \\
As an alternative to meat & 10.6 & 10.2 \\
Would definitely eat & 11.3 & 24.1 \\
Would possibly eat & 17.5 & 19.4 \\
Not sure & 20.6 & 16.7 \\
Would possibly not eat & 40.0 & 29.6 \\
Would definitely not eat &
\end{tabular}

Note: Results presented as percentages within the same age group.

\section{Food neophobia, meat, environment and health scores}

Food neophobia score was positively correlated with all willingness to try conditions as revealed from Spearman's correlation. The more neophobic the individual, the less willing they were to eat insects under all conditions tested (see Supplementary data). There was no correlation between meat score and health score (even when the three individual items that comprise the health score were tested individually) with the conditions tested. However, there was a weak correlation between environment score and willingness to try if they were affordable $(r=-0.125)$ as an alternative to meat $(r=-0.185)$ and, as expected, due to their environmental benefits ( $r=$ $-0.284)$.

\section{Willingness to try}

Analysis of the conditions against the question "are you willing to try insects" revealed the conditions that would make people change from willing to eat to not willing to eat and vice versa (see Table 7). There was a significant effect of willingness to try on all willingness to eat conditions $(P<0.001)$ as revealed from a chi-squared test. Higher percentages of those who were willing to try insects responded that they "would definitely eat" or "would possibly eat" for all conditions. Those who responded that they would not be willing to try insects could be persuaded to if the insects were tasty, if insects were used as a feed for livestock or if they were safe. On the other hand, those who responded that they would be willing to try insects could be dissuaded if they were to be eaten whole or as an alternative to meat.

\section{Previous knowledge}

The participants who had heard of entomophagy were willing to try insects under most of the conditions (see Table 7) except in the case of whole insects. 
Table 7: Effect of willingness to try, previous experience and knowledge on the conditions under which Irish participants are willing to consume insects

\begin{tabular}{|c|c|c|c|c|c|c|}
\hline \multirow[t]{2}{*}{ I would eat insects... } & \multicolumn{2}{|c|}{$\begin{array}{c}\text { Are you willing to try } \\
\text { insects? }\end{array}$} & \multicolumn{2}{|c|}{$\begin{array}{l}\text { Have you eaten } \\
\text { insects before? }\end{array}$} & \multicolumn{2}{|c|}{$\begin{array}{l}\text { Have you heard of } \\
\text { entomophagy? }\end{array}$} \\
\hline & Yes & No & Yes & No & Yes & No \\
\hline \multicolumn{7}{|l|}{ If they were whole } \\
\hline Would definitely eat & 84.2 & 15.8 & 27.8 & 3.9 & 10.4 & 1.9 \\
\hline Would possibly eat & 95.0 & 5.0 & 41.7 & 19.4 & 28.8 & 12.4 \\
\hline Not sure & 90.9 & 9.1 & 13.9 & 16.8 & 17.2 & 15.2 \\
\hline Would possibly not eat & 57.4 & 42.6 & 13.9 & 18.1 & 16.0 & 20.0 \\
\hline Would definitely not eat & 8.2 & 91.8 & 2.8 & 41.8 & 27.6 & 50.5 \\
\hline \multicolumn{7}{|c|}{ If they were disguised in a food I like } \\
\hline Would definitely eat & 94.0 & 6.0 & 55.6 & 20.3 & 34.4 & 10.5 \\
\hline Would possibly eat & 75.9 & 24.1 & 19.4 & 34.5 & 35.0 & 28.6 \\
\hline Not sure & 30.8 & 69.2 & 22.2 & 13.4 & 14.1 & 15.2 \\
\hline Would possibly not eat & 27.8 & 72.2 & 0.0 & 7.8 & 3.7 & 11.4 \\
\hline Would definitely not eat & 3.5 & 96.5 & 2.8 & 24.1 & 12.9 & 34.3 \\
\hline \multicolumn{7}{|l|}{ If they were affordable } \\
\hline Would definitely eat & 90.9 & 9.1 & 27.8 & 9.9 & 17.8 & 3.8 \\
\hline Would possibly eat & 89.6 & 10.4 & 38.9 & 22.8 & 31.9 & 14.3 \\
\hline Not sure & 73.8 & 26.2 & 33.3 & 22.8 & 24.5 & 23.8 \\
\hline Would possibly not eat & 29.0 & 71.0 & 0.0 & 13.4 & 9.2 & 15.2 \\
\hline Would definitely not eat & 1.4 & 98.6 & 0.0 & 31.0 & 16.6 & 42.9 \\
\hline \multicolumn{7}{|l|}{ If they were easily available } \\
\hline Would definitely eat & 93.3 & 6.7 & 30.6 & 8.2 & 17.2 & 1.9 \\
\hline Would possibly eat & 87.1 & 12.9 & 33.3 & 25.0 & 30.1 & 20.0 \\
\hline Not sure & 71.2 & 28.8 & 36.1 & 22.8 & 28.2 & 19.0 \\
\hline Would possibly not eat & 36.7 & 63.3 & 0.0 & 12.9 & 8.0 & 16.2 \\
\hline Would definitely not eat & 1.4 & 98.6 & 0.0 & 31.0 & 16.6 & 42.9 \\
\hline \multicolumn{7}{|l|}{ If they were safe } \\
\hline Would definitely eat & 95.0 & 5.0 & 44.4 & 19.0 & 30.7 & 9.5 \\
\hline Would possibly eat & 75.8 & 24.2 & 38.9 & 33.2 & 36.2 & 30.5 \\
\hline Not sure & 42.1 & 57.9 & 13.9 & 14.2 & 13.5 & 15.2 \\
\hline Would possibly not eat & 20.0 & 80.0 & 2.8 & 10.3 & 6.7 & 13.3 \\
\hline Would definitely not eat & 1.9 & 98.1 & 0.0 & 23.3 & 12.9 & 31.4 \\
\hline \multicolumn{7}{|l|}{ If they were nutritious } \\
\hline Would definitely eat & 94.6 & 5.4 & 33.3 & 19.0 & 27.6 & 10.5 \\
\hline Would possibly eat & 78.9 & 21.1 & 50.0 & 33.2 & 38.0 & 31.4 \\
\hline Not sure & 31.0 & 69.0 & 13.9 & 15.9 & 14.7 & 17.1 \\
\hline Would possibly not eat & 25.0 & 75.0 & 0.0 & 8.6 & 5.5 & 10.5 \\
\hline Would definitely not eat & 3.6 & 96.4 & 2.8 & 23.3 & 14.1 & 30.5 \\
\hline \multicolumn{7}{|l|}{ As an alternative to meat } \\
\hline Would definitely eat & 89.3 & 10.7 & 19.4 & 9.1 & 14.7 & 3.8 \\
\hline Would possibly eat & 84.1 & 15.9 & 22.2 & 15.5 & 19.6 & 11.4 \\
\hline Not sure & 69.4 & 30.6 & 16.7 & 18.5 & 21.5 & 13.3 \\
\hline
\end{tabular}


Table 7: (continued)

\begin{tabular}{|c|c|c|c|c|c|c|}
\hline \multirow[t]{2}{*}{ I would eat insects... } & \multicolumn{2}{|c|}{$\begin{array}{l}\text { Are you willing to try } \\
\text { insects? }\end{array}$} & \multicolumn{2}{|c|}{$\begin{array}{l}\text { Have you eaten } \\
\text { insects before? }\end{array}$} & \multicolumn{2}{|c|}{$\begin{array}{l}\text { Have you heard of } \\
\text { entomophagy? }\end{array}$} \\
\hline & Yes & No & Yes & No & Yes & No \\
\hline Would possibly not eat & 52.9 & 47.1 & 13.9 & 19.8 & 18.4 & 20.0 \\
\hline Would definitely not eat & 26.0 & 74.0 & 27.8 & 37.1 & 25.8 & 51.4 \\
\hline \multicolumn{7}{|l|}{ Due to the health benefits } \\
\hline Would definitely eat & 91.2 & 8.8 & 25.0 & 10.8 & 17.2 & 5.7 \\
\hline Would possibly eat & 74.2 & 25.8 & 33.3 & 34.9 & 35.0 & 34.3 \\
\hline Not sure & 61.1 & 38.9 & 30.6 & 18.5 & 23.3 & 15.2 \\
\hline Would possibly not eat & 42.9 & 57.1 & 5.6 & 11.2 & 11.0 & 9.5 \\
\hline Would definitely not eat & 5.1 & 94.9 & 5.6 & 24.6 & 13.5 & 35.2 \\
\hline \multicolumn{7}{|c|}{ Due to the environmental benefits } \\
\hline Would definitely eat & 91.9 & 8.1 & 19.4 & 12.9 & 19.0 & 5.7 \\
\hline Would possibly eat & 75.0 & 25.0 & 30.6 & 26.3 & 29.4 & 22.9 \\
\hline Not sure & 63.2 & 36.8 & 38.9 & 18.5 & 25.8 & 14.3 \\
\hline Would possibly not eat & 50.0 & 50.0 & 8.3 & 15.1 & 12.9 & 16.2 \\
\hline Would definitely not eat & 7.8 & 92.2 & 2.8 & 27.2 & 12.9 & 41.0 \\
\hline \multicolumn{7}{|l|}{ If they were tasty } \\
\hline Would definitely eat & 90.8 & 9.2 & 66.7 & 27.2 & 41.7 & 18.1 \\
\hline Would possibly eat & 60.2 & 39.8 & 19.4 & 32.8 & 30.1 & 32.4 \\
\hline Not sure & 45.8 & 54.2 & 11.1 & 8.6 & 8.6 & 9.5 \\
\hline Would possibly not eat & 28.0 & 72.0 & 2.8 & 10.3 & 9.2 & 9.5 \\
\hline Would definitely not eat & 2.0 & 98.0 & 0.0 & 21.1 & 10.4 & 30.5 \\
\hline \multicolumn{7}{|c|}{ If my family and friends were eating them } \\
\hline Would definitely eat & 93.3 & 6.7 & 22.2 & 9.5 & 17.8 & 1.0 \\
\hline Would possibly eat & 67.6 & 32.4 & 25.0 & 26.7 & 25.2 & 28.6 \\
\hline Not sure & 72.5 & 27.5 & 38.9 & 23.7 & 28.8 & 21.0 \\
\hline Would possibly not eat & 41.9 & 58.1 & 5.6 & 12.5 & 10.4 & 13.3 \\
\hline Would definitely not eat & 13.4 & 86.6 & 8.3 & 27.6 & 17.8 & 36.2 \\
\hline \multicolumn{7}{|c|}{ If the meat I was eating had been fed insects } \\
\hline Would definitely eat & 77.8 & 22.2 & 27.8 & 19.0 & 27.6 & 8.6 \\
\hline Would possibly eat & 65.0 & 35.0 & 25.0 & 22.0 & 22.7 & 21.9 \\
\hline Not sure & 65.3 & 34.7 & 30.6 & 27.6 & 27.6 & 28.6 \\
\hline Would possibly not eat & 38.5 & 61.5 & 2.8 & 10.8 & 7.4 & 13.3 \\
\hline Would definitely not eat & 15.1 & 84.9 & 13.9 & 20.7 & 14.7 & 27.6 \\
\hline
\end{tabular}

Note: Values represented as percentages. In each line total \% between YES and NO adds to $100 \%$.

Taste was the condition for which the largest proportion of those who had not heard of entomophagy before responded that they "would definitely eat" (18.1\%, Table 7$)$.

\section{Previous experience}

Participants who had eaten insects previously were more willing to try insects under most of the conditions, except in the cases where the meat they were eating had been fed with insects and as an alternative to meat. Under these two conditions, there were no significant differences in the answers between those who had tried insects against those who had not (Table 7). For example, a high proportion of those who had eaten insects before "would definitely eat" insects if they were used to feed livestock (27.8\%). The second highest 
majority of those who have not eaten insects before "would definitely eat" insects in this condition (19\%).

The highest proportion of "would definitely eat" responses among those who had eaten insects before $(66.7 \%)$ and among those who had not (27.2\%) was for taste. Still, there were significant differences in the score under this condition for the two groups $(P=0.004)$. The whole condition was an unpopular choice no matter if participants had eaten insects before or not, with the lowest proportions of "would definitely eat" responses of both those who had eaten insects before and those who had not being for whole $(21.2 \%$ and $3.9 \%$, respectively). Meat alternative was the condition for which the second largest proportions of those who had eaten insects before responded that they would not eat them $(27.8 \%)$.

\section{Other factors affecting willingness to eat}

The analysis of the open-ended questions revealed a number of other factors that could affect the willingness to consume insects of the Irish participants in the current study. As revealed from the open-ended question on which factors would influence your decision to consume insects or not, sensory appeal is the term mentioned more often among the participants (Figure 1). Sensory appeal along with the appropriate preparation and presentation would influence their willingness to consume insects. This agrees with the findings investigating the importance of the different conditions (Table 4 ), where it was found that taste was the most important factor. Insects would be consumed if they were presented or prepared in an appealing way, particularly if they were disguised into familiar foods.

Among the factors that would facilitate their decision to consume insects was their good nutritional content and the fact that their production is friendly to the environment. Moreover, a small number of participants would consume insects if they knew how they were prepared and where they were sourced. On the other hand, participants would not be willing to consume whole insects, because they find them disgusting and due to the lack of information in relation to their production and sourcing. Many participants were concerned about the safety of consuming insects, which is in agreement with the fact that safety is an important condition as revealed from the quantitative data.

Amongst the barriers that would affect consumption of insects are disgust, the prejudice of eating insects, the phobia of many participants of insects and the lack of information in relation to their safety and their nutritional value. On the other hand, knowing where the insects were sourced, the way they were produced, the concern about the environment, education and information in relation to their benefits are the facilitators that would lead people to possibly eat insects.

These barriers and facilitators were also revealed from the open-ended question what is your opinion about eating insects? The term most frequently mentioned (60 times overall) was disgust about insects. Lack of education and knowledge about insects led a number of participants to be reluctant towards eating them due to safety concern. However, many participants replied to the above question by saying they will eat insects because of their nutritional content, out of curiosity, necessity, to tackle food security and if it was part of their culture.

\section{Discussion}

The current survey focused on a segment of the Irish population living in a rural area of Ireland. Most participants were under 30 years of age and enrolled in third-level science courses. The vast majority had not tried insects before and only slightly more than half of the participants were willing to try insects, which was also observed in other studies conducted in Western countries (Caparros Megido et al., 2016). Gender in this study, as in previous ones (Schlup \& Brunner, 2018), was an important influencing factor. Indeed, the results revealed that more men had tried insects before; more men were willing to try insects than women and they were more willing to eat insects under most of the conditions questioned. This agrees with previous findings in relation to entomophagy (Hartmann et al., 2015; Verbeke, 2015) and novel foods such as genetically modified (McPhetres et al., 2019). Verbeke (2015) specifically found that younger men were more willing to consume insects. However, the current study revealed no effect of age on willingness to try except in the case of consuming insects as a meat alternative and when using insects to feed livestock, where younger people were less receptive to eating them. This could be due to the fact that a substantial number of students in the area come from farming backgrounds and previous research conducted in Flanders in Belgium has shown that farmers are more critical of adopting insects as feed for livestock (Verbeke et al., 2015). A difference between our study and those of Verbeke (2015) and Schlup \& Brunner (2018), who also found an effect of age, was that the participants of the previous studies were informed about the benefits of entomophagy as part of the study. Although the use of insects as feed for livestock is not a form of entomophagy, it is a way to insert insects into the food supply chain.

As in the case of age, education level had no effect on willingness to eat (except in the case of the condition "available") and this corroborates with previous research (Verbeke, 2015; Tan et al., 2016b). Despite the fact that undergraduate or postgraduate course type had no effect on willingness to try and on most of the conditions, undergraduate course type affected the willingness to consume insects as whole; more of those studying food/health and environmental 
(A)

\section{Other factors that would influence your decision TO EAT insects?}

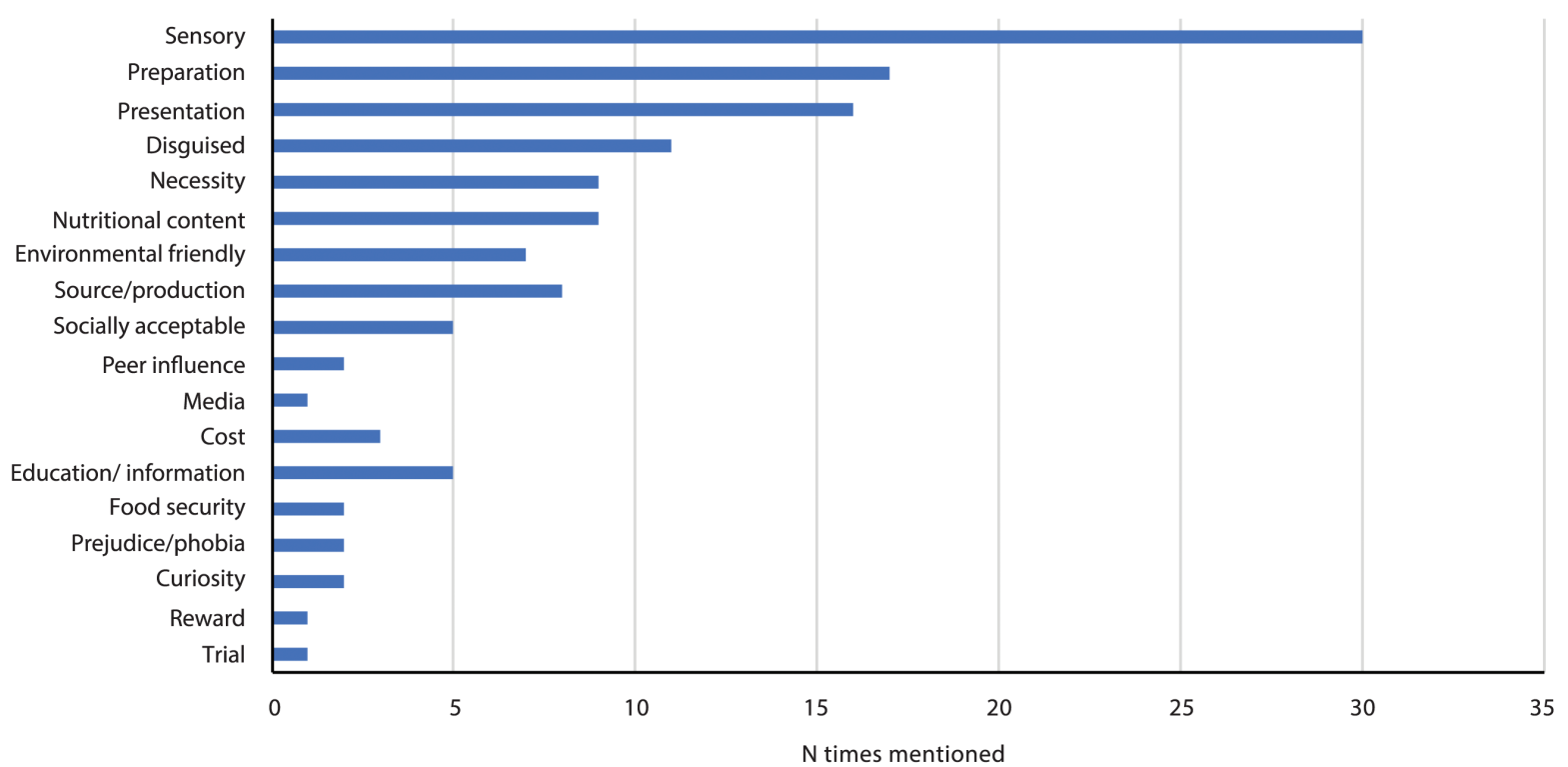

(B)

Other factors that would influence your decision NOT TO EAT insects?

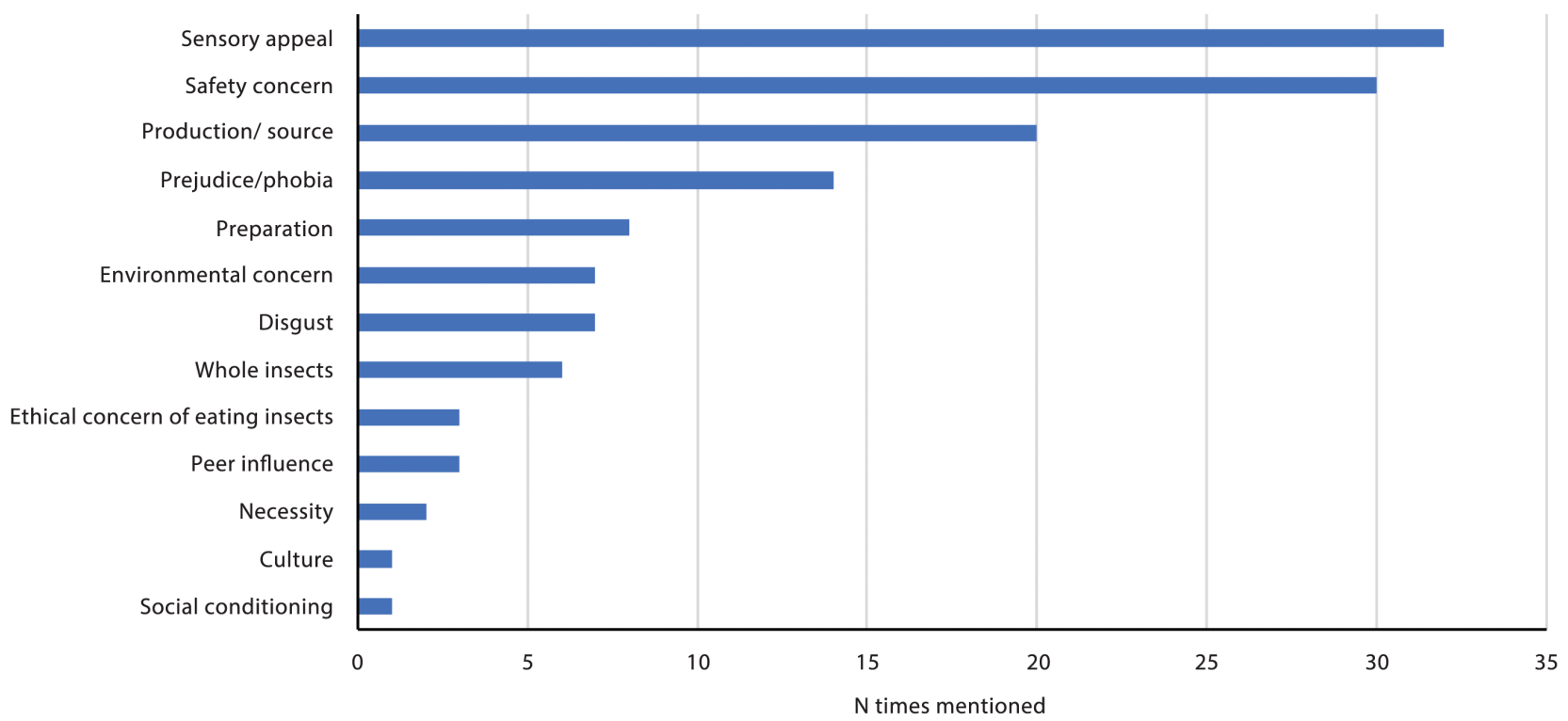

Figure 1. Frequency of factors that would influence the decision TO EAT insects (A) or NOT TO EAT insects (B), as revealed from the coding of the open-ended questions.

sciences were willing to consume insects under this condition. The latter partly agrees with the findings of Verbeke (2015) and Menozzi et al. (2017) who found that those who study environment and food sciences had a higher intention to consume insects.
Previous knowledge and previous experience were arguably the factors with the most influence over willingness to try among participants in this study, which is in agreement with findings of studies investigating entomophagy in other countries in Europe (Martins \& Pliner, 2005; Tan et al., 2015; 
Piha et al., 2018) and among US consumers (Woolf et al., 2019). Although only a small number of people in this study had previous experience with entomophagy, as was the case with participants from other Western countries (Caparros Megido et al., 2016), this affected their willingness to try under the different conditions studied. Significantly, more of those who had heard of entomophagy or who had eaten insects previously were willing to try insects under all the conditions investigated. This suggests that tasting insects could decrease neophobia and encourage people to become familiar with eating insects, as previously suggested (Caparros Megido et al., 2016).

Lack of previous knowledge of entomophagy overall had a negative impact on willingness to try as revealed from the qualitative data. Specifically, participants wrote comments suggesting that eating insects is unnecessary, that they didn't know how they would be farmed or prepared and that it would not be safe to eat insects due to contamination. These safety concerns are not unfounded; there are still some unknowns in relation to their microbiological and allergenic safety. However, common insects reared in controlled farming environments pose little risk to human health (Bessa et al., 2017). Some of the participants referred also to the phobia surrounding insects and the perception that they are disgusting. Indeed, disgust among participants in this study (and in others [Chan, 2019; Ruby \& Rozin, 2019]) could be linked to lack of knowledge and experience. However, research by Scott et al. (2016) into attitudes surrounding genetically modified foods suggests that those who express strong feelings of disgust towards novel foods may be "evidence insensitive" and so, efforts to change attitudes by increasing knowledge may prove futile among this cohort.

Factors relating to the diet such as low level of food neophobia, intention to reduce meat intake, high interest in health and environmental impact of food choice were found (Verbeke, 2015) to increase the likelihood of consuming insects. When the same methods of assessment (for neophobia, meat attachment, health and environment interest) were used in the current study, only food neophobia was found to be a significant indicator of willingness to try among the Irish participants, with those not willing to try scoring higher in the overall neophobia score. Higher levels of food neophobia also made participants less willing to consume insects under the various conditions studied. This corroborates with findings of previous studies where higher levels of food neophobia led to lower consumption intentions (Hartmann et al., 2015; Verbeke, 2015; Orsi et al., 2019) or lower acceptability of insect-containing products (Tan et al., 2016b). This suggests that those who enjoy trying new foods would be more willing to accept insects, a similar finding to a study that took place in Hungary (Gere et al., 2017), another European country in which insects are a novel food choice. Meat and health scores did not have an effect on willingness to try, and neither did the environment score. This agrees with a previous study (Lammers et al., 2019) of a group of German participants, where it was shown that sustainability was not a predictor of the willingness to consume insects. Environment score did, however, have an effect on the conditions "affordable", "meat alternative" and "environmental benefits", with those interested in the environmental impact of their food choices being more willing to consume under these conditions.

The current study also looked at the different diets followed by participants and it was found that more of those who followed vegetarian and vegan diets responded that they were not willing to try insects compared to those not following a specific diet. This could again be linked to the lack of knowledge about entomophagy, or it could suggest that vegetarians believe in the sentience of insects and to farm them or eat them would be a form of animal cruelty. However, $20 \%$ of vegetarians were willing to try insects, meaning that perhaps these people are vegetarians for reasons other than animal cruelty and are motivated by the environmental or health benefits of vegetarianism. This finding, along with the finding about those with a high environment score being more willing to try insects if they were a meat alternative and beneficial for the environment, indicates that this is a segment of the population who would be receptive to adopting entomophagy. This greater acceptance of entomophagy by those who are reducing their meat intake is in agreement with other European consumer acceptance studies (Verbeke, 2015; Gere et al., 2017) in Belgium and Hungary, respectively. Possibly in the future, a qualitative study using semi-structure interviews would give a better insight as to why some vegetarians are willing to try insects. Diet also had a significant effect on the conditions "meat fed insects" and "disguised", as vegetarians were less willing to consume insects under these conditions compared to the ones who do not follow a specific diet. These factors were highlighted in the qualitative data as well. In fact, sensory appeal was the most frequently mentioned code, closely followed by "nutritional content", "presentation" and "disguised". Sensory and visual characteristics of edible insects were important factors affecting consumer appeal, as revealed also by the comprehensive review conducted by Mishyna et al. (2020). A small number of participants were willing to try out of curiosity and because they considered it an interesting idea, although this number was not as high as in previous cases (Sogari et al., 2017), where it was suggested that curiosity along with environmental concern were the most important factors for the Italian consumers. The current study did not include a direct question on curiosity as in the case of Sogari et al. (2017) but this was a term revealed from the analysis of the answers to the question "which factors would influence your decision to eat insects". Some participants would try 
them only out of necessity and only if there was no other available food.

The willingness to eat conditions provided several very useful insights on the ways in which insects would be accepted among participants. Tasty was the most popular condition, with taste and sensory appeal being important factors affecting food choice as revealed by numerous studies related to food choice (Tucker, 2014; Tan et al., 2017a; Reed et al., 2019). On the other hand, whole was the least popular condition. This was further supported by the qualitative data, as some participants in the current study mentioned in response to the open-ended questions that they would eat insects if they were hidden in a familiar food for example, "if they were disguised in a steak". This is in agreement with previous work (Tan et al., 2017b) where Dutch consumers were more willing to try foods that contained invisible mealworm rather than visible. However, it must be noted that even in the case where insects are incorporated into a food product the carrier might also play an important role, as found by Lombardi et al. (2019) who studied the willingness of Italian consumers to pay for different insect-based foods.

The most interesting finding from the analysis of the conditions was the discovery of the conditions that made the willing-totry participants respond that they would not try insects in a particular condition and vice versa. This was a unique finding and offers a new insight into how those who initially respond that they would not be willing to try insect might become willing to do so under certain conditions. For example, taste would positively influence those who were not willing to try. Furthermore, they would be willing to consume insects if they had been used as feed for livestock. This presents an opportunity for Ireland to reduce the environmental impact of the agricultural industry, while also introducing insects into the food system. This could be a way to create a positive attitude towards insects as previously recommended (Looy et al., 2014), and to increase people's knowledge of insects as a source of food and therefore increase acceptance and willingness to consume insects. Unsurprisingly, those who were willing to try insects could be dissuaded from doing so if they were whole. It has been shown in other studies especially when comparing different cultures like the case of China and Germany: people who do not consume insects as part of their culture are less willing to consume them as whole or unprocessed (Hartmann et al., 2015). Some of the participants in the current study revealed that they do not perceive it to be socially acceptable to consume insects in Ireland, and that this would influence their decision to eat insects or not. This agrees with the findings of Jensen \& Lieberoth (2019), who suggested that perceived social norms play a substantial role in the (un)willingness of a Danish sample of participants to eat insects. However, as previously mentioned, those who had tried insects before were more willing to try insects in all conditions, including whole. This reveals that one of the most important methods of increasing acceptance of entomophagy in Ireland will be to persuade people to try insects for the first time through testing sessions.

\section{Conclusions}

This pilot study provided valuable information on the factors affecting willingness to try insects of a segment of the Irish population living in rural Ireland (Sligo). The study was limited to an educated sample, with uneven distributions of age, courses studied and diets. However, all factors were analysed using non-parametric tests which take the uneven distribution into account. A number of factors in line with related literature were tested through closed- and openended questions. This mixed-methods approach ensured the survey was relatively short and the response rate high. It also allowed for many of the relevant factors found in the literature that were not included in the quantitative questions, to possibly come up in the answers to the open-ended questions. This combination of data collection provided rich information on the factors affecting willingness to consume insects in this group of Irish consumers. It also provides a good basis for the development of surveys aimed at a more representative sample of the Irish population, to be conducted in the future.

The aim of this study was to identify the factors that affect willingness of a segment of the Irish population to consume insects, and the conditions under which people would be willing to consume them. Less food neophobic males who do not follow a particular diet are more receptive to adopting entomophagy in Ireland, according to the findings of this study. People who were willing to try insects were less likely to want to try them if they were whole, and those who were not willing to try insects could be persuaded to do so if the insect products were tasty or if they were to be used to feed livestock.

It was also found that food neophobia and disgust are major barriers against the acceptance of entomophagy in Ireland. These factors are difficult to tackle. Those who are neophobic will not be convinced to eat insects even if they are disguised, tasty or if insects were used to feed livestock. As those with more knowledge are more willing to try them, education about entomophagy will be important in increasing acceptance, particularly among those who are neophobic or disgusted by the concept. Analysis of the qualitative data revealed that people are lacking information on many different aspects of entomophagy, namely the farming and processing methods, the hygiene and safety and the health and environmental benefits. If education 
focuses on these areas, this could improve acceptance of entomophagy.

Education and taste tests will be important first steps to introducing entomophagy in Ireland. After this, tasty products containing invisible insects will be essential in order to maintain and increase acceptance. As insects are unlikely to be accepted as a meat alternative, a way to improve the negative impact of the agricultural industry, along with improving the public perception of entomophagy, will be to use insects to feed livestock. Therefore, further research needs to be conducted investigating the willingness of Irish farmers and relevant stakeholders to adopt insects as a feed for livestock.

\section{Acknowledgements}

The authors would like to thank Dr. Ioannis Manolakis for proof-reading the document.

\section{References}

Akhtar, Y. and Isman, M.B. 2018. Insects as an alternative protein source. In: "Proteins in Food Processing", 2nd Edition (ed. R.Y. Yada), Woodhead Publishing, Sawston, England, pages 263-288.

Baiano, A. 2020. Edible insects: an overview on nutritional characteristics, safety, farming, production technologies, regulatory framework, and socio-economic and ethical implications. Trends in Food Science \& Technology 100: 35-50.

Belluco, S., Losasso, C., Maggioletti, M., Alonzi, C.C., Paoletti, M.G. and Ricci, A. 2013. Edible insects in a food safety and nutritional perspective: a critical review. Comprehensive Reviews in Food Science and Food Safety 12: 296-313.

Bessa, L.W., Pieterse, E., Sigge, G. and Hoffman, L.C. 2017. Insects as human food; from farm to fork. Journal of the Science of Food and Agriculture 100: 5017-5022.

Caparros Megido, R., Gierts, C., Blecker, C., Brostaux, Y., Haubruge, É., Alabi, T. and Francis, F. 2016. Consumer acceptance of insectbased alternative meat products in Western countries. Food Quality and Preference 52: 237-243.

Chan, E.Y. 2019. Mindfulness and willingness to try insects as food: the role of disgust. Food Quality and Preference 71: 375-383.

Clune, S., Crossin, E. and Verghese, K. 2017. Systematic review of greenhouse gas emissions for different fresh food categories. Journal of Cleaner Production 140: 766-783.

Department of Communications Climate Action and Environment. 2018. "The Sustainable Development Goals National Implementation Plan 2018-2020". Available online: https://www. dccae.gov.ie/en-ie/news-and-media/publications/Documents/26/ DCCAE-National-Implementation-Plan.pdf [Accessed December 2018].
Deroy, O., Reade, B. and Spence, C. 2015. The insectivore's dilemma, and how to take the West out of it. Food Quality and Preference 44: 44-55.

Dossey, A.T., Tatum, J.T. and McGill, W.L. 2016. Chapter 5 - Modern insect-based food industry: current status, insect processing technology, and recommendations moving forward. In: "Insects as Sustainable Food Ingredients" (eds. A.T. Dossey, J.A. MoralesRamos and M.G. Rojas), Academic Press, San Diego, pages 113-152.

Dunn, O.J. 1964. Multiple comparisons using rank sums. Technometrics 6: 241-252.

Finke, M.D. and Oonincx, D. 2014. Chapter 17 - Insects as food for insectivores. In: "Mass Production of Beneficial Organisms" (eds. J.A. Morales-Ramos, M.G. Rojas and D.I. Shapiro-llan), Academic Press, San Diego, pages 583-616.

Gere, A., Székely, G., Kovács, S., Kókai, Z. and Sipos, L. 2017. Readiness to adopt insects in Hungary: a case study. Food Quality and Preference 59: 81-86.

Gere, A., Radványi, D. and Héberger, K. 2019. Which insect species can best be proposed for human consumption? Innovative Food Science \& Emerging Technologies 52: 358-367.

Gmuer, A., Nuessli Guth, J., Hartmann, C. and Siegrist, M. 2016. Effects of the degree of processing of insect ingredients in snacks on expected emotional experiences and willingness to eat. Food Quality and Preference 54: 117-127.

Godfray, H.C.J., Beddington, J.R., Crute, I.R., Haddad, L., Lawrence, D., Muir, J.F., Pretty, J., Robinson, S., Thomas, S.M. and Toulmin, C. 2010. Food security: the challenge of feeding 9 billion people. Science 327: 812-818.

Hartmann, C., Shi, J., Giusto, A. and Siegrist, M. 2015. The psychology of eating insects: a cross-cultural comparison between Germany and China. Food Quality and Preference 44: 148-156.

Jensen, N.H. and Lieberoth, A. 2019. We will eat disgusting foods together - evidence of the normative basis of Western entomophagy-disgust from an insect tasting. Food Quality and Preference 72: 109-115.

Kouřimská, L. and Adámková, A. 2016. Nutritional and sensory quality of edible insects. NFS Journal 4: 22-26.

La Barbera, F., Verneau, F., Amato, M. and Grunert, K. 2018. Understanding Westerners' disgust for the eating of insects: the role of food neophobia and implicit associations. Food Quality and Preference 64: 120-125.

Lammers, P., Ullmann, L.M. and Fiebelkorn, F. 2019. Acceptance of insects as food in Germany: is it about sensation seeking, sustainability consciousness, or food disgust? Food Quality and Preference 77: 78-88.

Lombardi, A., Vecchio, R., Borrello, M., Caracciolo, F. and Cembalo, L. 2019. Willingness to pay for insect-based food: the role of information and carrier. Food Quality and Preference 72: 177-187.

Looy, H., Dunkel, F.V. and Wood, J.R. 2014. How then shall we eat? Insect-eating attitudes and sustainable foodways. Agriculture and Human Values 31: 131-141. 
Martins, Y. and Pliner, P. 2005. Human food choices: an examination of the factors underlying acceptance/rejection of novel and familiar animal and nonanimal foods. Appetite 45: 214-224.

McPhetres, J., Rutjens, B.T., Weinstein, N. and Brisson, J.A. 2019. Modifying attitudes about modified foods: increased knowledge leads to more positive attitudes. Journal of Environmental Psychology 64: 21-29.

Menozzi, D., Sogari, G., Veneziani, M., Simoni, E. and Mora, C. 2017. Eating novel foods: an application of the Theory of Planned Behaviour to predict the consumption of an insect-based product. Food Quality and Preference 59: 27-34.

Mishyna, M., Chen, J. and Benjamin, O. 2020. Sensory attributes of edible insects and insect-based foods - future outlooks for enhancing consumer appeal. Trends in Food Science \& Technology 95: 141-148.

Myers, G. and Pettigrew, S. 2018. A qualitative exploration of the factors underlying seniors' receptiveness to entomophagy. Food Research International 103: 163-169.

Orsi, L., Voege, L.L. and Stranieri, S., 2019. Eating edible insects as sustainable food? Exploring the determinants of consumer acceptance in Germany. Food Research International 125: 108573.

Payne, C.L.R., Scarborough, P., Rayner, M. and Nonaka, K. 2016. A systematic review of nutrient composition data available for twelve commercially available edible insects, and comparison with reference values. Trends in Food Science \& Technology 47: 69-77.

Piha, S., Pohjanheimo, T., Lähteenmäki-Uutela, A., Křečková, Z. \& Otterbring, T. 2018. The effects of consumer knowledge on the willingness to buy insect food: an exploratory cross-regional study in Northern and Central Europe. Food Quality and Preference 70: 1-10.

Pliner, P. and Hobden, K. 1992. Development of a scale to measure the trait of food neophobia in humans. Appetite 19: 105-120.

Premalatha, M., Abbasi, T., Abbasi, T. and Abbasi, S.A. 2011. Energy-efficient food production to reduce global warming and ecodegradation: the use of edible insects. Renewable and Sustainable Energy Reviews 15: 4357-4360.

Reed, D.R., Mainland, J.D. and Arayata, C.J. 2019. Sensory nutrition: the role of taste in the reviews of commercial food products. Physiology \& Behavior 209: 112579.

Ruby, M.B. and Rozin, P. 2019. Disgust, sushi consumption, and other predictors of acceptance of insects as food by Americans and Indians. Food Quality and Preference 74: 155-162.

Schlup, Y. and Brunner, T. 2018. Prospects for insects as food in Switzerland: a tobit regression. Food Quality and Preference 64: 37-46.

Schösler, H., Boer, J.D. and Boersema, J.J. 2012. Can we cut out the meat of the dish? Constructing consumer-oriented pathways towards meat substitution. Appetite 58: 39-47.

Scott, S.E., Inbar, Y. and Rozin, P. 2016. Evidence for absolute moral opposition to genetically modified food in the United States. Perspectives on Psychological Science 11: 315-324.
Sheppard, B. and Frazer, P. 2015. Comparing social and intellectual appeals to reduce disgust of eating crickets. Studies in Arts and Humanities 1: 4-23.

Sogari, G., Menozzi, D. and Mora, C. 2017. Exploring young foodies' knowledge and attitude regarding entomophagy: a qualitative study in Italy. International Journal of Gastronomy and Food Science 7: 16-19.

Tan, H.S.G., Fischer, A.R. H., Tinchan, P., Stieger, M., Steenbekkers, L.P.A. and van Trijp, H.C.M. 2015. Insects as food: exploring cultural exposure and individual experience as determinants of acceptance. Food Quality and Preference 42: 78-89.

Tan, H.S.G., Fischer, A.R.H., van Trijp, H.C.M. and Stieger, M. 2016a. Tasty but nasty? Exploring the role of sensory-liking and food appropriateness in the willingness to eat unusual novel foods like insects. Food Quality and Preference 48: 293-302.

Tan, H.S.G., van den Berg, E. and Stieger, M. 2016b. The influence of product preparation, familiarity and individual traits on the consumer acceptance of insects as food. Food Quality and Preference 52: 222-231.

Tan, H.S.G., Tibboel, C.J. and Stieger, M. 2017a. Why do unusual novel foods like insects lack sensory appeal? Investigating the underlying sensory perceptions. Food Quality and Preference 60: 48-58.

Tan, H.S.G., Verbaan, Y.T. and Stieger, M. 2017b. How will better products improve the sensory-liking and willingness to buy insectbased foods?" Food Research International 92: 95-105.

Tucker, C.A. 2014. The significance of sensory appeal for reduced meat consumption. Appetite 81: 168-179.

United Nations. 2019. "Sustainable Development Goals". Available online: https://www.un.org/sustainabledevelopment/ [Accessed February 2019].

Verbeke, W. 2015. Profiling consumers who are ready to adopt insects as a meat substitute in a Western society. Food Quality and Preference 39: 147-155.

Verbeke, W., Spranghers, T., De Clercq, P., De Smet, S., Sas, B. and Eeckhout, M. 2015. Insects in animal feed: acceptance and its determinants among farmers, agriculture sector stakeholders and citizens. Animal Feed Science and Technology 204: 72-87.

Verneau, F., La Barbera, F., Kolle, S., Amato, M., Del Giudice, T. and Grunert, K. 2016. The effect of communication and implicit associations on consuming insects: an experiment in Denmark and Italy. Appetite 106: 30-36.

Wigglesworth, V.B. 2020. Insect. In: "Encyclopædia Britannica”. Available online: https://www.britannica.com/animal/insect [Accessed 28 November 2020].

Wilkinson, K., Muhlhausler, B., Motley, C., Crump, A., Bray, H. and Ankeny, R. 2018. Australian consumers' awareness and acceptance of insects as food. Insects 9: 44.

Woolf, E., Zhu, Y., Emory, K., Zhao, J. and Liu, C. 2019. Willingness to consume insect-containing foods: a survey in the United States. LWT 102: 100-105. 